\title{
Degradation of Abamectin Using the Photo-Fenton Process
}

\author{
Thiago Augusto de Freitas Matos, Alexandra Lemos Nunes Dias, Amanda Di Piazza Reis, \\ Milady Renata Apolinário da Silva, and Márcia Matiko Kondo
}

\author{
ICE-DFQ, Universidade Federal de Itajubá, Avenida BPS 1303, 37500-903 Itajubá, MG, Brazil \\ Correspondence should be addressed to Márcia Matiko Kondo, marciamkondo@gmail.com
}

Received 15 October 2011; Revised 11 January 2012; Accepted 16 January 2012

Academic Editor: Licínio M. Gando-Ferreira

Copyright (C 2012 Thiago Augusto de Freitas Matos et al. This is an open access article distributed under the Creative Commons Attribution License, which permits unrestricted use, distribution, and reproduction in any medium, provided the original work is properly cited.

\begin{abstract}
The cultivation of strawberries generally requires substantial use of pesticides, and abamectin is the active principle of one of those most commonly employed. Conventional water treatment does not remove pesticides efficiently, so there is a need to investigate alternative procedures. The use of advanced oxidation processes (AOPs) can achieve good results in removal of toxic organic compounds present in aqueous solutions. The photo-Fenton process, one example of an AOP, was employed to study the degradation of abamectin. Results showed that when natural water samples contaminated with abamectin were treated using the photo-Fenton process, $70 \%$ of the initial amount of the compound was removed within 60 minutes of UV irradiation, and $60 \%$ mineralization was observed after 180 minutes of reaction.
\end{abstract}

\section{Introduction}

Biocides are one of the most important classes of compounds introduced into surface waters by human activities [1]. They are widely used in agriculture and can contaminate rivers and other water bodies due to transport from cultivated areas [2-5]. Although the pesticide industry has developed new compounds that are more effective, even at lower concentrations, and that present lower environmental impacts [6], the misuse of such pesticides can pose considerable toxicity risks to operators, consumers, and the wider environment [7].

The cultivation of strawberries uses large amounts of pesticides. One of the most commonly employed is Vertimec 18 EC, which contains $1.8 \%(\mathrm{w} / \mathrm{v})$ of abamectin, the active principle. Abamectin belongs to the avermectin group and has the molecular formula $\mathrm{C}_{48} \mathrm{H}_{72} \mathrm{O}_{14}$ (avermectin $\mathrm{Bla}$ ) + $\mathrm{C}_{47} \mathrm{H}_{70} \mathrm{O}_{14}$ (avermectin $\mathrm{Blb}$ ). It is used primarily as a biocide. Abamectin is a toxic chemical and can be fatal if inhaled, ingested, or absorbed by the skin. It causes skin and eye irritation, and at high doses can cause damage to the central nervous system (CAS no., 71751-41-2). The substance is also highly toxic to fish and aquatic invertebrates. The maximum acceptable daily intake (ADI) is $0.01 \mathrm{mg} \mathrm{kg}^{-1}$ body weight, and the maximum residue limit is $0.02 \mathrm{mg} \mathrm{kg}^{-1}$ of the commercial product [8].

Effluents containing biocides cannot usually be treated efficiently using biological techniques, since the effluents are toxic to the microorganisms involved so that the biodegradation efficiency is reduced [9].

An alternative treatment that has been investigated is based on the use of advanced oxidation processes (AOPs), which are very efficient for the removal of potentially toxic organic compounds from water systems. In AOPs, hydroxyl radicals $(\bullet \mathrm{OH})$ are formed as highly reactive intermediates, and can mineralize organic compounds to $\mathrm{H}_{2} \mathrm{O}, \mathrm{CO}_{2}$, and mineral acids [10-13].

The photo-Fenton process, an AOP, has attracted considerable interest due to its high efficiency in producing hydroxyl radicals during $\mathrm{H}_{2} \mathrm{O}_{2}$ decomposition catalysed by $\mathrm{Fe}^{2+}$ in acid solution under UV irradiation (1) and (2) [14]. Advantages of this process include the ability to use relatively low-cost reagents, and solar irradiation as the UV source. At the end of the process, the iron ions present can 
be precipitated by increasing the $\mathrm{pH}$, while the $\mathrm{H}_{2} \mathrm{O}_{2}$ is consumed during the reaction [15]:

$$
\begin{gathered}
\mathrm{Fe}^{2+}+\mathrm{H}_{2} \mathrm{O}_{2} \longrightarrow \mathrm{Fe}^{3+}+\mathrm{OH}^{-}+\cdot \mathrm{OH}, \\
\mathrm{Fe}^{3+}+\mathrm{H}_{2} \mathrm{O}+h v \longrightarrow \mathrm{Fe}^{2+}+\cdot \mathrm{OH}+\mathrm{H}^{+}
\end{gathered}
$$

The ${ }^{\circ} \mathrm{OH}$ generated can degrade organic pollutants present in aqueous solutions. Parameters such as $\mathrm{pH}$ and reagent concentration ratios must be controlled, in order to enhance the efficiency of the degradation process. The optimum $\mathrm{pH}$ range for the Fenton and photo-Fenton processes is 2.5-3.0 [16, 17]. The use of an excess amount of $\mathrm{H}_{2} \mathrm{O}_{2}$ can reduce the efficiency, since hydrogen peroxide can scavenge ${ }^{\bullet} \mathrm{OH}$, generating ${ }^{\bullet} \mathrm{HO}_{2}$ which has a lower reducing potential than the hydroxyl radical $[18,19]$.

Fenton and photo-Fenton processes have been successfully employed to treat a variety of effluents containing compounds such as dyes [20], antibiotics [21, 22], landfill leachates [23], and emerging contaminants [24].

The Federal University of Itajubá (Universidade Federal de Itajubá) is located in one of the major strawberry cultivation areas of Brazil. The objective of the present paper was to investigate the degradation efficiency of abamectin using the photo-Fenton process with UV irradiation.

\section{Experimental}

2.1. Pesticide Solutions. Abamectin solutions were prepared from the commercially available pesticide, in distilled water at a concentration of $9 \mathrm{mg} \mathrm{L}^{-1}\left(400 \mathrm{mg} \mathrm{L}^{-1}\right.$ TOC). This concentration is the same as that used by farmers during strawberry cultivation.

2.2. Photo-Fenton Process. Iron nitrate $\left(0.5 \mathrm{mmol} \mathrm{L}^{-1}\right)$ was added to the abamectin solution, and the $\mathrm{pH}$ was adjusted to 2.5 using $1.0 \mathrm{~mol} \mathrm{~L}^{-1} \mathrm{H}_{2} \mathrm{SO}_{4}$. The photoreactor consisted of an UV lamp $\left(\mathrm{Hg}, 125 \mathrm{~W}, \lambda_{\max }=365 \mathrm{~nm}\right)$, inserted into a double jacket whereby the system could be cooled by water recirculation, and was immersed in the reaction solution. $6.0 \mathrm{mmol} \mathrm{L}^{-1}$ of $\mathrm{H}_{2} \mathrm{O}_{2}$ was added to the abamectin solution, and the lamp was turned on to start the reaction $\left(17 \mathrm{~mW} \mathrm{~cm}^{-2}\right.$, as measured by a Cole-Parmer radiometer, series 9811). Samples were withdrawn at predetermined intervals, over periods of 60 or 180 minutes. To halt the Fenton reaction, the $\mathrm{pH}$ was raised to $\mathrm{pH} 10$ using $6.0 \mathrm{~mol} \mathrm{~L}^{-1} \mathrm{NaOH}$, in order to precipitate iron hydroxide. The supernatant was separated by centrifugation and used for the different chemical analyses. The choice of $\mathrm{pH}$ value and the $\mathrm{H}_{2} \mathrm{O}_{2}$ and $\mathrm{Fe}^{3+}$ concentrations was based on previous work that used the Fenton reaction to treat another herbicide [25-27].

Natural water samples from the José Pereira stream $\left(22^{\circ} 24^{\prime} 50^{\prime \prime} \mathrm{S}\right.$ and $45^{\circ} 24^{\prime} 02^{\prime \prime} \mathrm{W}$, in WGS 84 datum) were also spiked with the same concentration of abamectin and irradiated under the conditions already described. The objective of these tests was to study the efficiency of the Fenton reaction under conditions more representative of those arising from agricultural contamination.
Experiments were also performed without irradiation (Fenton process), using the $\mathrm{H}_{2} \mathrm{O}_{2} / \mathrm{UV}$ advanced oxidative process. Control experiments using UV alone (direct photolysis), $\mathrm{H}_{2} \mathrm{O}_{2}$ alone, and iron alone with UV were conducted in order to evaluate the influence of each parameter on the degradation process.

2.3. Abamectin Quantification. Abamectin was quantified by GC/FID using a Varian Model CP 3380 instrument equipped with an AB-5 column $(25 \mathrm{~m} \times 0.25 \mathrm{~mm} \times 0.25 \mu \mathrm{m})$. Aliquots $(1 \mu \mathrm{L})$ of the eluted samples were injected into the GC. The operating conditions of the oven were an initial temperature of $50^{\circ} \mathrm{C}$ for 1 minute, a ramp to $200^{\circ} \mathrm{C}$ at $15^{\circ} \mathrm{C}$ $\mathrm{min}^{-1}$, and a final hold at $200^{\circ} \mathrm{C}$ for 1 minute. The injector temperature was $240^{\circ} \mathrm{C}$, and the FID detector temperature was $300^{\circ} \mathrm{C}$. All samples were injected 4 times, and the results were calculated as averages. All experiments were performed in triplicate.

Analytical grade abamectin (Sigma-Aldrich) was used to generate the calibration curve. The detection limit (DL) and quantification limit (QL) were calculated using the ratio of the standard deviation (s) and the slope (S) of the calibration curve (3) and (4) [28]:

$$
\begin{aligned}
& \mathrm{DL}=3.3 \times(\mathrm{s} / \mathrm{S}), \\
& \mathrm{QL}=10 \times(\mathrm{s} / \mathrm{S})
\end{aligned}
$$

Since the abamectin solution used for the degradation experiments was prepared from a commercially available pesticide that contained other compounds, it was necessary to separate the abamectin from the aqueous solutions prior to the chromatographic analyses. This was achieved by solid phase extraction using Waters Sep-Pak $C_{18}$ cartridges [29]. After the degradation process, the samples were centrifuged in order to separate out the iron precipitate. The supernatant $(50 \mathrm{~mL})$ was passed through the Sep-Pak cartridge at a flow

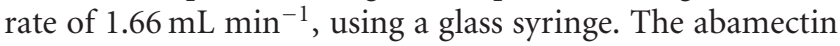
retained in the cartridge was then eluted with an aqueous solution containing $85 \%$ methanol. This extract was used for abamectin quantification using GC.

2.4. Statistical Analysis. The statistical analysis employed $\mathrm{R}$ software and its complement Tinn-R [30] and considered the data to be randomly distributed. The residuals of the data were determined, together with the homogeneity of the variances. The multiple comparison analysis used the Tukey test (at a 5\% significance level).

2.5. Hydrogen Peroxide Determination. The hydrogen peroxide concentration was monitored spectrophotometrically using the metavanadate method [31].

2.6. Total Organic Carbon (TOC). The mineralization of organic material in the solution during the photodegradation was monitored by quantifying total organic carbon (TOC) using a carbon analyser (TOC 5000A, Shimadzu). These analyses were performed in the laboratory of the LAPOA 
group, at the Institute of Chemistry, UNESP (Araraquara, São Paulo, Brazil).

\section{Results and Discussion}

Determination of abamectin is usually performed by liquid chromatography [32-35]. At present there are no reports in the literature concerning analysis of the compound by gas chromatography, so that a new method therefore needed to be developed. Injection of a methanolic solution of abamectin showed that it eluted at a retention time of 5.7 minutes. Validation of an analytical method involving a separation technique (such as GC) requires determination of parameters including the linearity of the analytical curve, the DL, and the QL [28]. The calibration curve obtained here showed good linearity, with a high correlation coefficient (0.9988). The calculated detection and quantification limits were $0.0168 \mathrm{mg} \mathrm{L}^{-1}$ and $0.0511 \mathrm{mg} \mathrm{L}^{-1}$, respectively, which are low compared to the initial pesticide concentration. Repeatable quantification of abamectin was achieved after separation using Sep-Pak cartridges, showing that the method was also selective. These results demonstrated that the technique used to quantify abamectin met the requirements of the present paper, which were to identify abamectin and monitor its concentration with precision during the photo-Fenton treatment process.

3.1. Control Experiments. In order to understand the influence of the different experimental variables on the degradation of abamectin, experiments were performed using each variable individually. Combinations of variables (such as iron and UV) were also employed. Figure 1 shows the comparative results obtained for these tests.

Abamectin was destroyed by direct photolysis, with 39\% removal after 1 hour of irradiation (Figure 1). This result indicates that the pesticide could be photodegraded if present in surface water within the photic zone. Mushtaq et al. [36] showed that avermectin, the chemical group to which abamectin belongs, was also degraded by direct photolysis in natural water after 22 days of solar irradiation. Nevertheless, direct photolysis will not occur in the natural environment when the compound is absorbed in the sediment, or when it is present below the photic zone.

Kamel et al. [37] studied the degradation of abamectin in Saudi Arabian soil. Removal rates of $66 \%$ and $88 \%$ were observed after 7 and 14 days of solar irradiation, respectively. However, the residual concentration remained higher than that permitted by legislation.

When iron was used alone, together with UV, there was $45 \%$ abamectin removal after 60 minutes of irradiation. This probably indicates that photoactive complexes formed between iron and other compounds present in the original pesticide sample, and/or their intermediates, were generated during the degradation process $[25,38]$. Similar behaviour was observed by Park et al. [39] using the dye Acid Orange 7, by Silva et al. [25] during photo-Fenton degradation of the herbicide tebuthiuron using solar irradiation, and by Sun

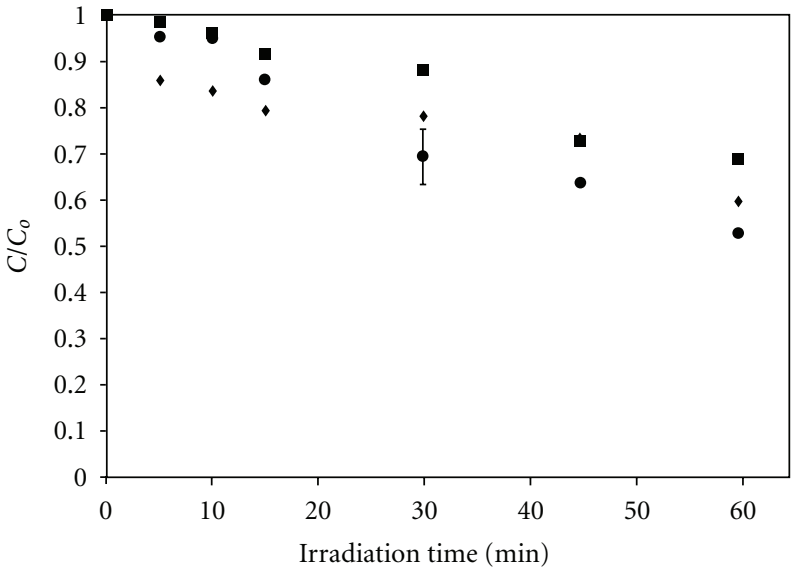

FIGURE 1: Comparison of the efficiency of degradation of abamectin using different treatments: $-\longrightarrow$ direct photolysis; $-\square-\mathrm{H}_{2} \mathrm{O}_{2}$; - - Fe + UV. Initial conditions: $\left[\mathrm{H}_{2} \mathrm{O}_{2}\right]=6.0 \mathrm{mmol} \mathrm{L}-1 ;\left[\mathrm{Fe}^{3+}\right]$ $=0.5 \mathrm{mmol} \mathrm{L}^{-1}$; abamectin $=9.0 \mathrm{mg} \mathrm{L}^{-1}, \lambda=365 \mathrm{~nm} ; \mathrm{pH}=2.5$.

and Pignatello [40], who attributed the second stage of 2,4$\mathrm{D}$ degradation to iron complex photolysis in the presence of pesticide degradation intermediates. The relatively high degradation efficiency obtained here is interesting since there was no use of $\mathrm{H}_{2} \mathrm{O}_{2}$, which could reduce the costs of treatment.

For more than 30 years, the use of $\mathrm{H}_{2} \mathrm{O}_{2}$, a strong oxidant, has been commonplace in treatments involving oxidation of organic and inorganic pollutants $[41,42]$. In the present paper, use of $\mathrm{H}_{2} \mathrm{O}_{2}$ alone (in the absence of irradiation) resulted in 30\% removal of abamectin after 60 minutes (Figure 1).

3.2. Degradation Studies. Considering that in the control experiments abamectin removal was in the region of only $30 \%$ to $45 \%$, the efficiency of degradation of the compound was also investigated using three different AOPs. Figure 2 shows the results of abamectin degradation using Fenton and photo-Fenton reactions, and the $\mathrm{H}_{2} \mathrm{O}_{2} / \mathrm{UV}$ system.

In the experiments using the Fenton reaction, there was $40 \%$ abamectin removal after 1 hour of irradiation. Similar degradation efficiency was observed after the same time interval using $\mathrm{H}_{2} \mathrm{O}_{2} / U V$. Due to the radiation source used, which had a wavelength limit of $\lambda_{\max }=365 \mathrm{~nm}$, the UV radiation was not able to cause $\mathrm{H}_{2} \mathrm{O}_{2}$ decomposition, which requires a wavelength near $254 \mathrm{~nm}$ [43]. In the present study, the UV radiation probably only acted to remove abamectin by direct photolysis.

Use of the photo-Fenton system improved abamectin degradation, with up to $55 \%$ removal after 30 minutes of reaction, and $80 \%$ removal after 60 minutes of irradiation. Similar results were obtained by Pignatello [16], who showed that the photo-Fenton process was more efficient than the Fenton process for degradation of 2,4-dichlorophenoxyacetic acid, since photo-reduction of $\mathrm{Fe}^{3+}$ ions to $\mathrm{Fe}^{2+}$ increased the catalytic effect. The $\mathrm{Fe}^{2+}$ ions can react again with $\mathrm{H}_{2} \mathrm{O}_{2}$, and continue the Fenton reaction. The results obtained in 


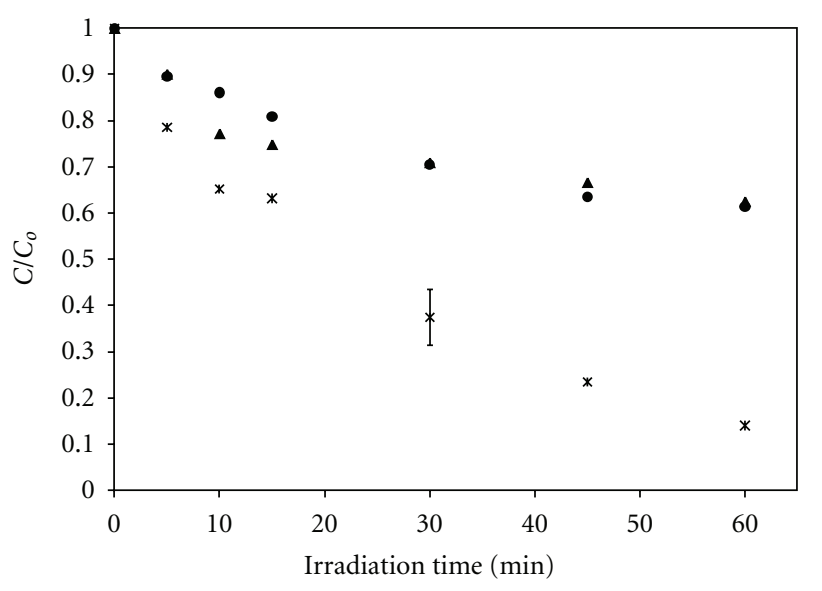

Figure 2: Comparison of degradation efficiency of abamectin using different AOPs: - $-\boldsymbol{\Delta}-\mathrm{H}_{2} \mathrm{O}_{2} / \mathrm{UV} ;-\longrightarrow-$ Fenton reaction; - $*-$ photo-Fenton reaction. Initial conditions: $\left[\mathrm{H}_{2} \mathrm{O}_{2}\right]=6.0 \mathrm{mmol} \mathrm{L}^{-1}$; $\left[\mathrm{Fe}^{3+}\right]=5.0 \mathrm{mmol} \mathrm{L}^{-1}$; abamectin $=9.0 \mathrm{mg} \mathrm{L}^{-1}, \lambda=365 \mathrm{~nm} ; \mathrm{pH}=$ 2.5.

the present paper indicate that the photo-Fenton process is effective for the treatment of water and effluents contaminated with abamectin, with a high removal rate within a short irradiation period of up to 60 minutes.

The hydrogen peroxide concentration is an important parameter influencing Fenton and photo-Fenton processes. At high concentrations it can be detrimental to the degradation of organic compounds in water, since excess $\mathrm{H}_{2} \mathrm{O}_{2}$ can act as radical scavenger [44]. On the other hand, a lack of $\mathrm{H}_{2} \mathrm{O}_{2}$ interrupts the Fenton reaction, because its absence can halt hydroxyl radical production and, consequently, destruction of organic compounds. Therefore, monitoring the $\mathrm{H}_{2} \mathrm{O}_{2}$ concentration can help in adjustment of its initial concentration, and identify any need for further addition during the Fenton process.

Monitoring $\mathrm{H}_{2} \mathrm{O}_{2}$ levels showed that after 60 minutes there was a residual concentration of at least $10 \%$ of the initial concentration, and that there was therefore no need to add more $\mathrm{H}_{2} \mathrm{O}_{2}$ during the period of irradiation.

Figure 3 shows the outcome of the multiple comparison tests (Tukey's test at 5\% level of significance) applied to the results of the degradation experiments. The photoFenton reaction (a) presented higher abamectin degradation efficiency than the other treatments. The Fe/UV treatment (b) showed better degradation efficiency compared to the $\mathrm{H}_{2} \mathrm{O}_{2}$ and $\mathrm{H}_{2} \mathrm{O}_{2} / \mathrm{UV}$ treatments (c). The results using UV alone and the Fenton process were statistically similar to the results obtained for $\mathrm{Fe} / \mathrm{UV}, \mathrm{H}_{2} \mathrm{O}_{2}$ alone, and $\mathrm{H}_{2} \mathrm{O}_{2} / \mathrm{UV}$. These results indicated that each individual process could degrade abamectin to some extent; however, the best results were obtained using the photo-Fenton process.

\subsection{Photo-Fenton Degradation of Abamectin in Natural} Aquatic Samples. Abamectin removal by the photo-Fenton process reached $80 \%$ using solutions prepared in distilled water. In order to investigate removal of the pesticide under more natural conditions, the influences of the different

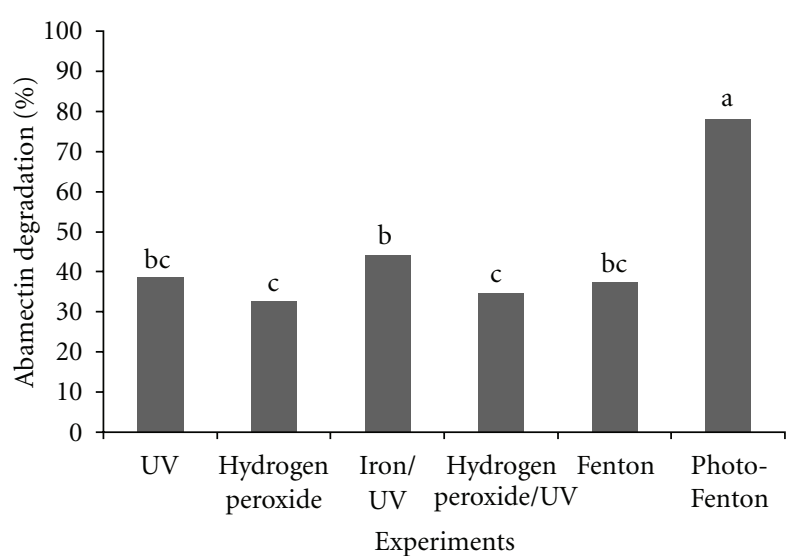

FIgURE 3: Multiple comparison tests for the different processes applied to abamectin removal. The same letters above the means for the different procedures indicates that statistically there were no differences between the procedures, using Tukey's test at a 5\% level of significance. Conditions: $\left[\mathrm{H}_{2} \mathrm{O}_{2}\right]=6.0 \mathrm{mmol} \mathrm{L}-1$; $\left[\mathrm{Fe}^{3+}\right]=$ $0.5 \mathrm{mmol} \mathrm{L}{ }^{-1}$; abamectin $=9.0 \mathrm{mg} \mathrm{L}^{-1} ; \lambda=365 \mathrm{~nm}$; initial $\mathrm{pH}=2.5$.

physical and chemical parameters were investigated using water samples collected from the José Pereira stream, which were spiked with abamectin. Samples were collected on rainy and dry days. The water collected on a dry day showed values of $120 \mathrm{mg} \mathrm{L}^{-1}$ of total solids and $2 \mathrm{mg} \mathrm{L}^{-1}$ of BOD, while the sample collected during precipitation showed values of $307 \mathrm{mg} \mathrm{L}^{-1}$ of total solids and $4 \mathrm{mg} \mathrm{L}^{-1}$ of BOD. A comparison of abamectin degradation using either distilled water or the natural water samples is shown in Figure 4. It has been reported that organic compound degradation decreases in the presence of natural organic matter and solids, due to reduced penetration of UV radiation. The organic material can compete with the target compound for hydroxyl radicals and/or form complexes with iron, which reduces the efficiency of Fenton degradation [45]. However, even given the possible interferences, abamectin degradation under these conditions reached $70 \%$ after 60 minutes of reaction. No difference was observed between degradation of the pesticide in natural water samples collected on rainy or dry days.

3.4. TOC Analysis. Although the results showed that abamectin could be degraded, there was no significant difference in the TOC values after 60 minutes of irradiation. This suggests that abamectin was not mineralised, but that intermediates were generated during the reaction. In a similar study, Fallmann et al. [46] used the photo-Fenton process to treat an aqueous solution containing $100 \mathrm{ppm}$ (TOC) of Vertimec, and observed $20 \%$ mineralization after 50 minutes of irradiation, achieving $90 \%$ after 150 minutes. However, the authors used a smaller quantity of initial TOC compared to the amount used in the present work (400 ppm). In another study, Bauer et al. [43] used the photo-Fenton reaction to treat a liquid effluent containing a mixture of 10 different pesticides, including Vertimec. The authors used an initial TOC concentration of $10 \mathrm{ppm}$ of each 


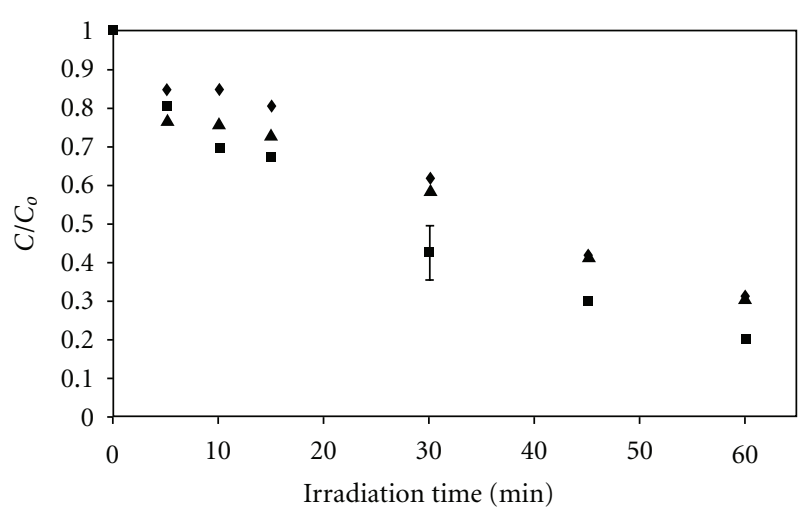

Figure 4: Comparison of abamectin degradation using the photo-Fenton process for: - $-\mathbf{\Delta}$ - natural water; $-\longrightarrow$ natural water (rainy day); - - distilled water. Conditions: $\left[\mathrm{H}_{2} \mathrm{O}_{2}\right]=$ $6.0 \mathrm{mmol} \mathrm{L}^{-1} ;\left[\mathrm{Fe}^{3+}\right]=0.5 \mathrm{mmol} \mathrm{L}^{-1} ;$ abamectin $=9.0 \mathrm{mg} \mathrm{L}^{-1} ; \lambda=$ $365 \mathrm{~nm}$; initial $\mathrm{pH}=2.5$.

pesticide in distilled water, which was treated in a solar UV reactor $(300-400 \mathrm{~nm})$. For the photo-Fenton process they used a concentration of $10^{-3} \mathrm{mmol} \mathrm{L}^{-1} \mathrm{FeSO}_{4} \cdot 7 \mathrm{H}_{2} \mathrm{O}$ and 33 wt $\%$ of $\mathrm{H}_{2} \mathrm{O}_{2}$, which was added in five portions. TOC removal was in excess of $80 \%$ after 3 hours of irradiation using the solar photo-Fenton process. The results of these two earlier studies suggest that in the present work, where the Vertimec solution contained an initial $400 \mathrm{ppm}$ of TOC, the irradiation time and the amount of $\mathrm{H}_{2} \mathrm{O}_{2}$ were probably not sufficient to achieve pesticide mineralization.

Additional experiments were therefore performed in order to try to improve removal of TOC. In an attempt to reproduce the results obtained by Fallmann et al. [46], the initial concentration of TOC was decreased from $400 \mathrm{ppm}$ to $100 \mathrm{ppm}$ of Vertimec, the $\mathrm{H}_{2} \mathrm{O}_{2}$ concentration was raised to $20 \mathrm{mmol} \mathrm{L}^{-1}$, with an iron concentration of $0.5 \mathrm{mmol} \mathrm{L}{ }^{-1}$. The exposure time was increased to 180 minutes, in line with that employed by Fallmann et al. [46]. The results of these studies, with a ratio $\mathrm{Fe} / \mathrm{H}_{2} \mathrm{O}_{2}$ of 0.0833 , showed that $60 \%$ of TOC was removed after 180 minutes. This result is very similar to those reported by Bauer et al. [43] and Fallmann et al. [46].

The possibility of reducing treatment costs was studied by decreasing the $\mathrm{Fe} / \mathrm{H}_{2} \mathrm{O}_{2}$ ratio used for mineralization of $400 \mathrm{ppm}$ (TOC) of Vertimec. Using iron and $\mathrm{H}_{2} \mathrm{O}_{2}$ concentrations of $1.0 \mathrm{mmol} \mathrm{L}^{-1}$ and $80 \mathrm{mmol} \mathrm{L}^{-1}$, respectively $\left(\mathrm{Fe} / \mathrm{H}_{2} \mathrm{O}_{2}\right.$ ratio of 0.0125$)$, there was $60 \%$ TOC removal after 180 minutes of irradiation. A further experiment was performed employing $0.5 \mathrm{mmol} \mathrm{L}^{-1}$ of iron and $80 \mathrm{mmol} \mathrm{L}^{-1}$ of $\mathrm{H}_{2} \mathrm{O}_{2}\left(\mathrm{Fe} / \mathrm{H}_{2} \mathrm{O}_{2}\right.$ ratio of 0.00625$)$; however, there was no observable removal of TOC. These results showed that there was a limiting amount of reagents required to achieve TOC removal. Abamectin could be degraded using $\mathrm{Fe} / \mathrm{H}_{2} \mathrm{O}_{2}$ ratios smaller than 0.0125; however, there was no change in the TOC value, indicating that both the original organic compound and TOC should be monitored in order to ensure detoxification of the solution.

Studies of the toxicity and biodegradability of the possible reaction intermediates will be essential in order to establish the optimum concentrations of the photo-Fenton reagents. Future investigations should provide information that addresses the need to effectively mineralize the pesticide, or at least degrade it to a nontoxic intermediate. Additional work is also needed to investigate the possibility of combining a biological process with the photo-Fenton treatment described in the present work.

\section{Conclusions}

Determination of abamectin by gas chromatography was successfully used to assess the efficiency of degradation of the pesticide by the photo-Fenton process.

The photo-Fenton process was shown to be an effective treatment for water and effluents contaminated with abamectin, achieving a high removal rate of $70 \%$ of the chemical after 60 minutes of UV irradiation. Increasing the concentrations of $\mathrm{Fe}^{2+}$ and $\mathrm{H}_{2} \mathrm{O}_{2}$ enabled attainment of at least $60 \%$ pesticide mineralization after 180 minutes of irradiation.

\section{Acknowledgments}

The authors would like to thank CNPq, CAPES/REUNI, and FAPEMIG for financial support; Dr. José Roberto Guimarães (UNICAMP); Dr. Raquel F. Pupo Nogueira (UNESP) for assistance with the analytical procedures.

\section{References}

[1] Z. Huang, Y. Li, B. Chen, and S. Yao, "Simultaneous determination of 102 pesticide residues in Chinese teas by gas chromatography-mass spectrometry," Journal of Chromatography B, vol. 853, no. 1-2, pp. 154-162, 2007.

[2] I. K. Konstantinou, D. G. Hela, and T. A. Albanis, "The status of pesticide pollution in surface waters (rivers and lakes) of Greece. Part I. Review on occurrence and levels," Environmental Pollution, vol. 141, no. 3, pp. 555-570, 2006.

[3] A. J. Dos Santos Neto and M. E. P. B. De Siqueira, "Analysis of organophosphorus pesticides in water using SPE C18 disks and gas chromatography: evaluation of Furnas dam contamination," Química Nova, vol. 28, no. 5, pp. 747-750, 2005.

[4] M. J. Cerejeira, P. Viana, S. Batista et al., "Pesticides in Portuguese surface and ground waters," Water Research, vol. 37, no. 5, pp. 1055-1063, 2003.

[5] E. Maloschik, A. Ernst, G. Hegedus, B. Darvas, and A. Székács, "Monitoring water-polluting pesticides in Hungary," Microchemical Journal, vol. 85, no. 1, pp. 88-97, 2007.

[6] F. P. Carvalho, "Agriculture, pesticides, food security and food safety," Environmental Science and Policy, vol. 9, no. 7-8, pp. 685-692, 2006.

[7] N. D. Uri, "A note on the development and use of pesticides," Science of the Total Environment, vol. 204, no. 1, pp. 57-74, 1997.

[8] Joint FAO/WHO Food Standards Program, Codex Committee on Pesticide Residues, CX/PR 97/9 pp. 159, 1997.

[9] M. B. Kralj, P. Trebše, and M. Franko, "Applications of bioanalytical techniques in evaluating advanced oxidation processes in pesticide degradation," Trends in Analytical Chemistry, vol. 26, no. 11, pp. 1020-1031, 2007. 
[10] R. Andreozzi, V. Caprio, A. Insola, and R. Marotta, "Advanced oxidation processes (AOP) for water purification and recovery," Catalysis Today, vol. 53, no. 1, pp. 51-59, 1999.

[11] V. Claret Dos Santos and M. M. Kondo, " $\mathrm{TiO}_{2}$ immobilizan onto concrete: chloroform and phenol photodegradation," Química Nova, vol. 29, no. 2, pp. 251-255, 2006.

[12] M. Klavarioti, D. Mantzavinos, and D. Kassinos, "Removal of residual pharmaceuticals from aqueous systems by advanced oxidation processes," Environment International, vol. 35, no. 2, pp. 402-417, 2009.

[13] D. Hermosilla, M. Cortijo, and C. P. Huang, "Optimizing the treatment of landfill leachate by conventional Fenton and photo-Fenton processes," Science of the Total Environment, vol. 407, no. 11, pp. 3473-3481, 2009.

[14] J. J. Pignatello, E. Oliveros, and A. MacKay, "Advanced oxidation processes for organic contaminant destruction based on the fenton reaction and related chemistry," Critical Reviews in Environmental Science and Technology, vol. 36, no. 1, pp. 1-84, 2006.

[15] R. F. Pupo Nogueira, A. G. Trovó, M. R. A. Da Silva, R. D. Villa, and M. C. De Oliveira, "Fundaments and environmental applications of Fenton and photo-Fenton processes," Química Nova, vol. 30, no. 2, pp. 400-408, 2007.

[16] J. J. Pignatello, "Dark and photoassisted $\mathrm{Fe}^{3+}$-catalyzed degradation of chlorophenoxy herbicides by hydrogen peroxide," Environmental Science and Technology, vol. 26, no. 5, pp. 944951, 1992.

[17] R. F. Pupo Nogueira and J. R. Guimarães, "Photodegradation of dichloroacetic acid and 2,4-dichlorophenol by ferrioxalate $/ \mathrm{H}_{2} \mathrm{O}_{2}$ system," Water Research, vol. 34, no. 3, pp. 895-901, 2000.

[18] J. A. Herrera-Melián, E. Tello Rendón, J. M. Doña Rodríguez et al., "Incidence of pretreatment by potassium permanganate on hazardous laboratory wastes photodegradability," Water Research, vol. 34, no. 16, pp. 3967-3976, 2000.

[19] E. Balanosky, F. Herrera, A. Lopez, and J. Kiwi, "Oxidative degradation of textile waste water. Modeling reactor performance," Water Research, vol. 34, no. 2, pp. 582-596, 2000.

[20] T. Maezono, M. Tokumura, M. Sekine, and Y. Kawase, "Hydroxyl radical concentration profile in photo-Fenton oxidation process: generation and consumption of hydroxyl radicals during the discoloration of azo-dye Orange II," Chemosphere, vol. 82, pp. 1422-1430, 2010.

[21] M. Pérez-Moya, M. Graells, G. Castells et al., "Characterization of the degradation performance of the sulfamethazine antibiotic by photo-Fenton process," Water Research, vol. 44, no. 8, pp. 2533-2540, 2010.

[22] O. Rozas, D. Contreras, M. A. Mondaca, M. Pérez-Moya, and H. D. Mansilla, "Experimental design of Fenton and photoFenton reactions for the treatment of ampicillin solutions," Journal of Hazardous Materials, vol. 177, no. 1-3, pp. 10251030, 2010.

[23] V. J. P. Vilar, E. M. R. Rocha, F. S. Mota, A. Fonseca, I. Saraiva, and R. A. R. Boaventura, "Treatment of a sanitary landfill leachate using combined solar photo-Fenton and biological immobilized biomass reactor at a pilot scale," Water Research, vol. 45, no. 8, pp. 2647-2658, 2011.

[24] N. Klamerth, L. Rizzo, S. Malato, M. I. Maldonado, A. Agüera, and A. R. Fernández-Alba, "Degradation of fifteen emerging contaminants at $\mu \mathrm{g} \mathrm{L}^{-1}$ initial concentrations by mild solar photo-Fenton in MWTP effluents," Water Research, vol. 44, no. 2, pp. 545-554, 2010.
[25] M. R. A. Silva, A. G. Trovó, and R. F. P. Nogueira, "Degradation of the herbicide tebuthiuron using solar photo-Fenton process and ferric citrate complex at circumneutral $\mathrm{pH}$," Journal of Photochemistry and Photobiology A, vol. 191, no. 2-3, pp. 187192, 2007.

[26] M. R. A. Silva, W. Vilegas, M. V. B. Zanoni, and R. F. Pupo Nogueira, "Photo-Fenton degradation of the herbicide tebuthiuron under solar irradiation: iron complexation and initial intermediates," Water Research, vol. 44, no. 12, pp. 3745-3753, 2010.

[27] M. M. Kondo, K. U. C. G. Leite, M. R. A. Silva, and A. D. P. Reis, "Fenton and photo-fenton processes coupled to uasb to treat coffee pulping wastewater," Separation Science and Technology, vol. 45, no. 11, pp. 1506-1511, 2010.

[28] M. Ribani, C. B. Grespan Bottoli, C. H. Collins, I. C. S. Fontes Jardim, and L. F. Costa Melo, "Validation for chromatographic and electrophoretic methods," Quimica Nova, vol. 27, no. 5, pp. 771-780, 2004.

[29] J. Hernández-Borges, L. M. Ravelo-Pérez, E. M. HernándezSuárez, A. Carnero, and M. A. Rodríguez-Delgado, "Analysis of abamectin residues in avocados by high-performance liquid chromatography with fluorescence detection," Journal of Chromatography A, vol. 1165, no. 1-2, pp. 52-57, 2007.

[30] R Development Core Team, R: A Language and Environment for Statistical Computing, R Foundation for Statistical Computing, Vienna, Austria, 2009.

[31] R. F. P. Nogueira, M. C. Oliveira, and W. C. Paterlini, "Simple and fast spectrophotometric determination of $\mathrm{H}_{2} \mathrm{O}_{2}$ in photoFenton reactions using metavanadate," Talanta, vol. 66, no. 1, pp. 86-91, 2005.

[32] H. Diserens and M. Henzelin, "Determination of abamectin residues in fruits and vegetables by high-performance liquid chromatography," Journal of Chromatography A, vol. 833, no. 1, pp. 13-18, 1999.

[33] A. I. Valenzuela, D. S. Popa, M. J. Redondo, and J. Mañes, "Comparison of various liquid chromatographic methods for the analysis of avermectin residues in citrus fruits," Journal of Chromatography A, vol. 918, no. 1, pp. 59-65, 2001.

[34] M. Danaher, L. C. Howells, S. R. H. Crooks, V. CerkvenikFlajs, and M. O'Keeffe, "Review of methodology for the determination of macrocyclic lactone residues in biological matrices," Journal of Chromatography B, vol. 844, no. 2, pp. 175-203, 2006.

[35] M. D. Hernando, J. M. Suárez-Barcena, M. J. M. Bueno, J. F. Garcia-Reyes, and A. R. Fernández-Alba, "Fast separation liquid chromatography-tandem mass spectrometry for the confirmation and quantitative analysis of avermectin residues in food," Journal of Chromatography A, vol. 1155, no. 1, pp. 62-73, 2007.

[36] M. Mushtaq, A. C. Chukwudebe, C. Wrzesinski, L. R. S. Allen, D. Luffer-Atlas, and B. H. Arison, "Photodegradation of emamectin benzoate in aqueous solution," Journal of Agricultural and Food Chemistry, vol. 46, no. 3, pp. 1181-1191, 1998.

[37] A. Kamel, S. Al-Dosary, S. Ibrahim, and M. Asif Ahmed, "Degradation of the acaricides abamectin, flufenoxuron and amitraz on Saudi Arabian dates," Food Chemistry, vol. 100, no. 4, pp. 1590-1593, 2007.

[38] R. F. P. Nogueira, M. R. A. Silva, and A. G. Trovó, "Influence of the iron source on the solar photo-Fenton degradation of different classes of organic compounds," Solar Energy, vol. 79, no. 4, pp. 384-392, 2005.

[39] J. S. Park, K. H. Kim, G. J. Kwon et al., "Development of small and efficient ozone generation using corona discharge," KorusPhysics, vol. 1, pp. 282-284, 2001. 
[40] Y. Sun and J. J. Pignatello, "Photochemical reactions involved in the total mineralization of $2,4-\mathrm{D}$ by $\mathrm{Fe}^{3+} / \mathrm{H}_{2} \mathrm{O}_{2} / \mathrm{UV}$," Environmental Science and Technology, vol. 27, no. 2, pp. 304310, 1993.

[41] E. Neyens and J. Baeyens, "A review of classic Fenton's peroxidation as an advanced oxidation technique," Journal of Hazardous Materials, vol. 98, no. 1-3, pp. 33-50, 2003.

[42] R. Venkatadri and R. W. Peters, "Chemical oxidation technologies: ultraviolet light/hydrogen peroxide, Fenton's reagent, and titanium dioxide-assisted photocatalysis," Hazardous Waste and Hazardous Materials, vol. 10, no. 2, pp. 107-149, 1993.

[43] R. Bauer, G. Waldner, H. Fallmann et al., "The photo-fenton reaction and the $\mathrm{TiO}_{2} / \mathrm{UV}$ process for waste water treatmentnovel developments," Catalysis Today, vol. 53, no. 1, pp. 131144, 1999.

[44] W. C. Paterlini and R. F. P. Nogueira, "Multivariate analysis of photo-Fenton degradation of the herbicides tebuthiuron, diuron and 2,4-D," Chemosphere, vol. 58, no. 8, pp. 1107-1116, 2005.

[45] R. G. Zepp, B. C. Faust, and J. Holgné, "Hydroxyl radical formation in aqueous reactions $(\mathrm{pH} \mathrm{3-8)}$ of iron(II) with hydrogen peroxide: the photo-fenton reaction," Environmental Science and Technology, vol. 26, no. 2, pp. 313-319, 1992.

[46] H. Fallmann, T. Krutzler, R. Bauer, S. Malato, and J. Blanco, "Applicability of the Photo-Fenton method for treating water containing pesticides," Catalysis Today, vol. 54, no. 2-3, pp. 309-319, 1999. 

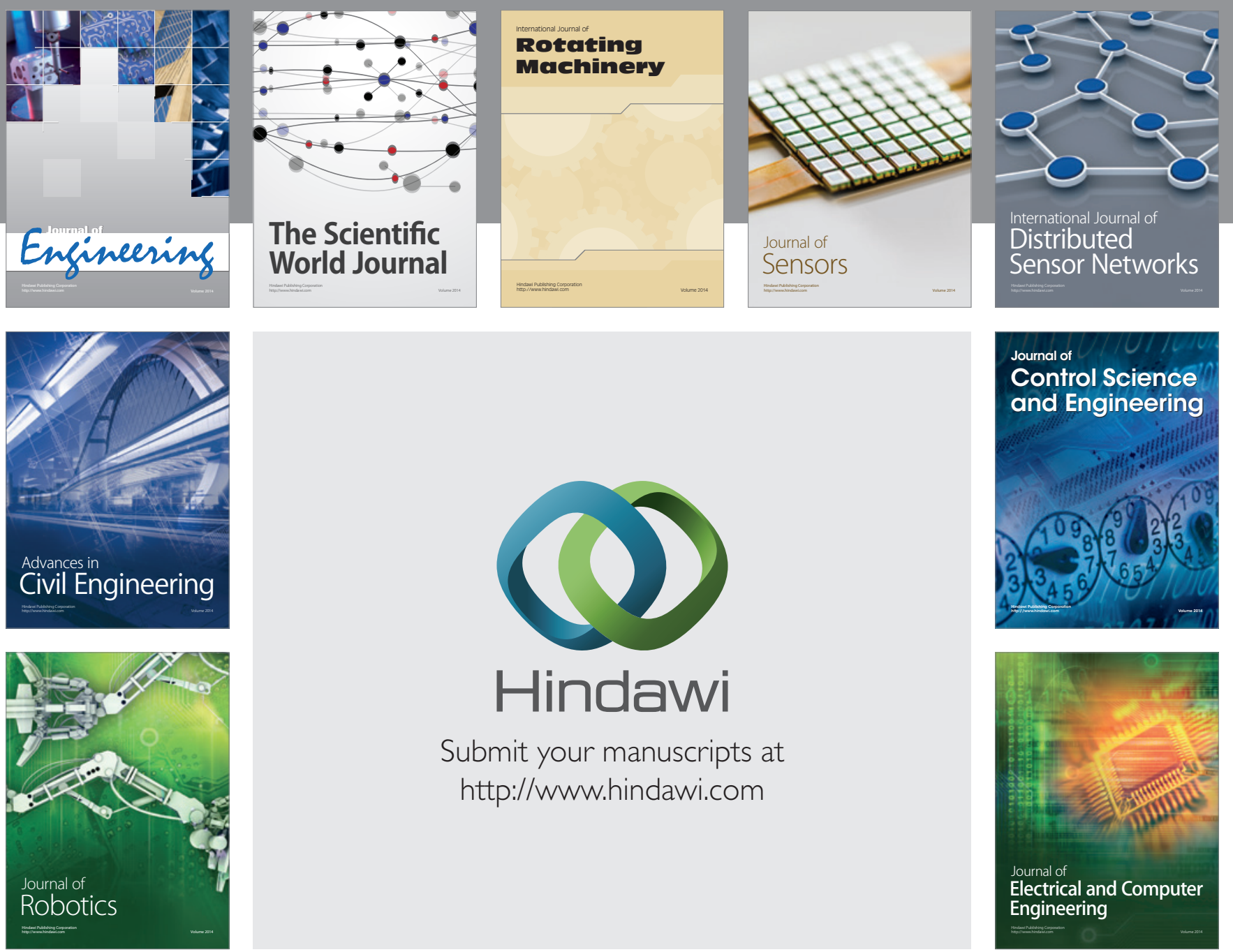

Submit your manuscripts at

http://www.hindawi.com
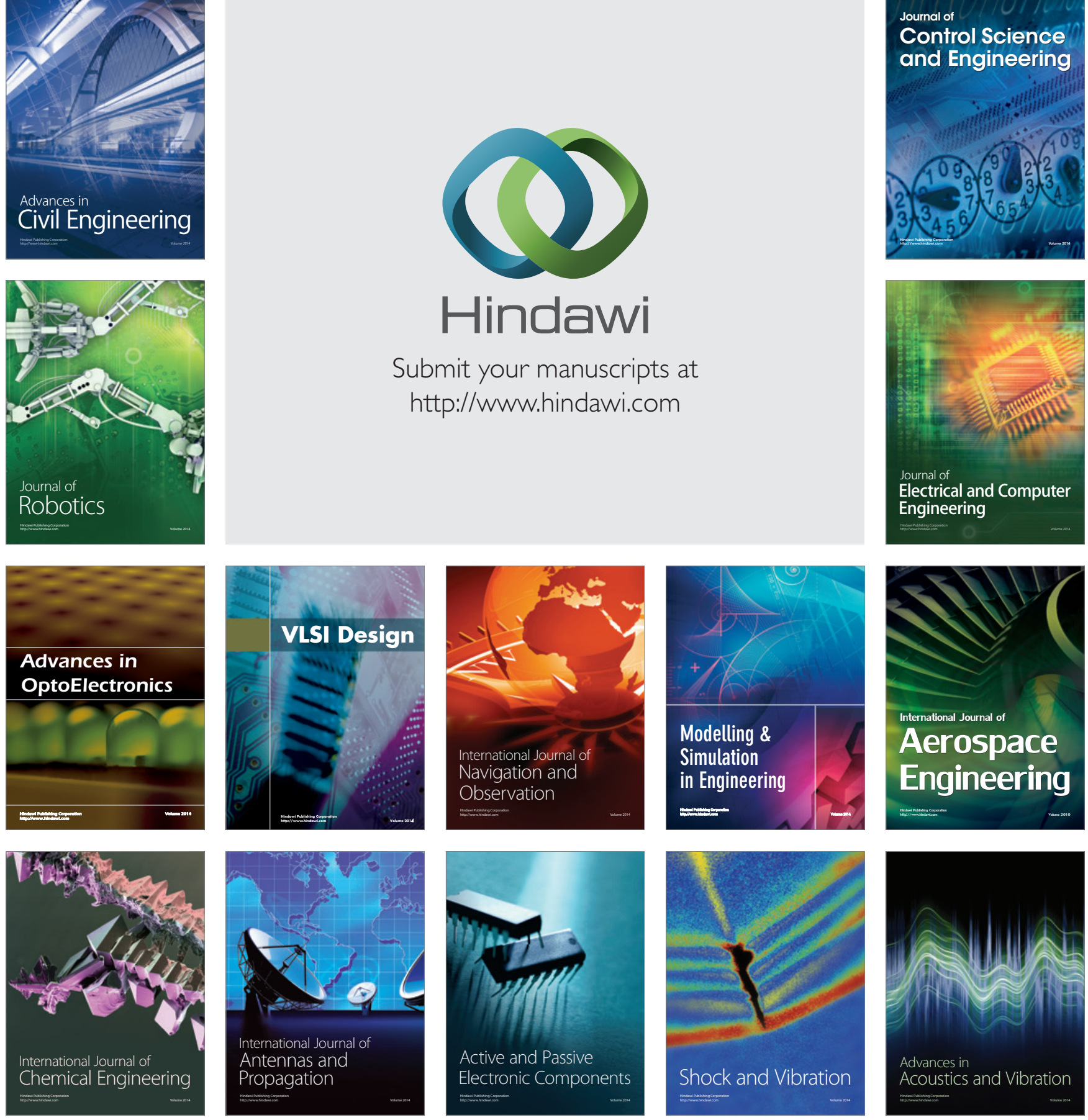